\title{
Outcome predictors of intravenous thrombolytic therapy in acute ischemic stroke patients: an Egyptian center experiences
}

Mohamed A. Tork, Hany M. Aref, Hala M. El-Khawas, Mohamed F. Khalil and Ahmed ElSadek

\begin{abstract}
Background: Intravenous thrombolytic therapy remains the guideline-recommended treatment to improve outcomes after acute ischemic stroke. However, the functional outcome among patients with acute ischemic stroke after receiving intravenous thrombolytic therapy is influenced by huge variety of factors, and this was the aim of our study to evaluate the outcome predictors of intravenous thrombolytic therapy in a sample of Egyptian patients with acute ischemic stroke.
\end{abstract}

Methods: We enrolled 183 acute ischemic stroke patients who were treated with intravenous recombinant tissue plasminogen activator (IV rtPA) according to the last updated guidelines of American Heart Association and American Stroke Association (AHA/ASA) from February 2018 to February 2020; however, only 150 patients of them completed our study plan till the end. Data of study variables were collected, analyzed statistically and correlated with the functional outcome 3 months after receiving IV rtPA using the modified Rankin Scale (mRS).

Results: Good functional outcome was seen in 98 (65.3\%) patients and poor functional outcome was seen in 52 (34.7\%) patients. Multivariate analysis of the study variables was done to detect the significant independent predictors of the functional outcome. Atrial fibrillation (AF) ( $P$ value $<0.001^{*}$ OR $6.28^{*}(95 \%$ C.I)), hypertension $(P$ value $0.001^{*}$ OR $3.65^{*}\left(95 \%\right.$ C.I)), diabetes mellitus (DM) (P value $0.009^{*}$ OR $2.805^{*}(95 \%$ C.I)), increased National Institute of Health Stroke Scale (NIHSS) score $24 \mathrm{~h}$ after receiving IV rtPA (P value $0.003^{*}$ OR $8.039^{*}(95 \%$ C.I)), increased pulsatility index (PI) value in cerebral vessels at the same side of stroke lesion ( $P$ value $0.038^{*}$ OR $42.48^{*}(95 \%$ C.I)) were the significant independent predictors of poor functional outcome. On the other hand decreased NIHSS score $24 \mathrm{~h}$ after receiving IV rtPA $\left(P\right.$ value $0.003^{*}$ OR $0.124^{*}(95 \%$ C.I)), Normal value of PI in cerebral vessels at the same side of stroke lesion ( $P$ value $0.038^{*}$ OR $42.48^{*}(95 \%$ C.I)) were the significant independent predictors of good functional outcome.

Conclusion: Intravenous thrombolytic therapy improves the functional outcome of acute ischemic stroke patients. Also, AF, hypertension, DM, NIHSS $24 \mathrm{~h}$ after receiving IV rtPA and PI could be used as independent predictors of the functional outcome.

Keywords: Acute ischemic stroke, Thrombolytic therapy, Pulsatility Index, Functional outcome predictors

\footnotetext{
*Correspondence: ahmedelsadek_79@yahoo.com

Neurology Department, Ain Shams University, Cairo, Egypt
}

\section{Springer Open}

(c) The Author(s). 2020 Open Access This article is licensed under a Creative Commons Attribution 4.0 International License, which permits use, sharing, adaptation, distribution and reproduction in any medium or format, as long as you give appropriate credit to the original author(s) and the source, provide a link to the Creative Commons licence, and indicate if changes were made. The images or other third party material in this article are included in the article's Creative Commons licence, unless indicated otherwise in a credit line to the material. If material is not included in the article's Creative Commons licence and your intended use is not permitted by statutory regulation or exceeds the permitted use, you will need to obtain permission directly from the copyright holder. To view a copy of this licence, visit http://creativecommons.org/licenses/by/4.0/. 


\section{Introduction}

Stroke is the second most common cause of death, and accounts for $11 \%$ of total deaths in 2015 and the fifth leading cause of death in the USA, also more than $80 \%$ of strokes are ischemic strokes [1, 2]. Stroke burden on families and society was projected to rise from approximately 38 million disability-adjusted life years (DALYs) lost globally in 1990 to 61 million DALYs in 2020 due to population ageing and is projected to further rise till 2030 [3]. In Egypt, the most populated nation in the Middle East, the overall crude prevalence rate of stroke is high $(963 / 100,000$ inhabitants) [4]. The official national statistics indicate that diseases of the circulatory system, including stroke, are the primary cause of death in Egypt [5].

Intravenous thrombolytic therapy remains the guideline-recommended treatment to improve outcomes after acute ischemic stroke, especially in patients without proximal arterial occlusion, and is associated with low complication rates [6]. Intravenous thrombolytic therapy improves functional outcome at three to six months when given within $4.5 \mathrm{~h}$ of ischemic stroke onset [7]. There has been an extensive investigation of prognostic indices of good outcomes that can be applied before, during, and after thrombolysis [8]. The benefit of intravenous thrombolysis for acute ischemic stroke decreases continuously over time from symptom onset, as shown in meta-analyses of randomized trials $[9,10]$.

It is well known that factors, such as age, initial NIHS $\mathrm{S}$ score, and systolic blood pressure, are of predictive value for clinical outcome and symptomatic intracerebral hemorrhage (sICH) [11]. Magnetic resonance imaging (MRI), computed tomography (CT), and transcranial doppler (TCD) have also been used as possible prognostic determinant tools. In particular, arterial occlusion, recanalization, and reocclusion, among other factors, have been investigated in terms of outcome prediction [12]. We aimed in this study to evaluate the functional outcome of intravenous thrombolytic therapy in a sample of Egyptian patients with acute ischemic stroke and correlate it with possible predictors.

\section{Methods}

We enrolled initially in this longitudinal cohort study 183 patients with acute ischemic stroke aged between 18 and 80 years old and who received IV rtPA in the first $4.5 \mathrm{~h}$ time window from the onset of stroke symptoms from February 2018 to February 2020. Fourteen patients did not accept to participate, 3 patients were lost during the first few days after admission who were discharged against medical advice, 9 patients were expired due to causes not related to thrombolytic therapy like cardiac and respiratory complications, 7 patients were lost during follow up at three months, and only 150 patients of them completed the study plan till the end who were subjected to statistical analysis.

All inclusion and exclusion criteria were based on AHA/ASA last updated guidelines. Additional exclusion criteria were applied to patients who had in-hospital complications or death due to causes other than that related to thrombolytic therapy, patients who were not available for follow up, discharged against medical advice and were not content for enrolling in this study. All patients were subjected upon hospital arrival to full general, vital, and neurological examinations, urgent routine laboratory sampling, and CT brain without contrast. All patients after receiving IV rtPA were transferred to stroke care units.

We analyzed patients demographic data (age and gender), baseline characteristics, location of stroke lesion based on brain and cerebral vessels imaging which included CT brain, computerized tomography angiography (CTA), MRI brain with diffusion, magnetic resonance angiography (MRA), and was classified into anterior circulation and posterior circulation ischemic stroke. Stroke severity was assessed at time of admission and 24 $\mathrm{h}$ after IV rtPA using NIHSS which is a tool used by healthcare providers to objectively quantify the impairment caused by a stroke [13, 14]. Door to needle time which is a parameter of efficiency of acute stroke care system was assessed. Also, we assessed timing of IV rtPA administration from onset of stroke symptoms which is a possible potential predictor of the functional outcome. Comorbidities which are potential stroke risk factors were included: hypertension, coronary artery disease (CAD), DM, AF, smoking and hyperlipidemia. We assessed the presence of intracranial \pm extracranial atherosclerosis or stenosis using MRA, CTA, carotid, and vertebrobasilar duplex with $5-10 \mathrm{MHz}$ linear probe, Esaote Mylab5-Italy. Also, transcranial color-coded duplex (TCCD) with phased array $(2-4 \mathrm{MHz})$ probe, Esaote Mylab5-Italy, was done $24 \mathrm{~h}$ after receiving IV rtPA and the PI in the cerebral vessels at the same side of stroke lesion was measured. Major and minor complications of IV rtPA treatment after infusion and during hospital stay were analyzed especially intracerebral hemorrhage (ICH). Functional outcome 3 months after receiving IV rtPA was assessed using mRS which is a tool used to assess the functional status of the stroke survivors $[15,16]$.

All the previous data were collected, analyzed, and correlated with the mRS 3 months after receiving IV rtPA.

Stroke severity was categorized into mild stroke, when the NIHSS score was $\leq 8$; moderate stroke when the NIHSS score was from 9 to 15; and severe stroke when the NIHSS score was $\geq 16$ [17]. Patients with mRS score of 2 or less were considered to have a good functional 
outcome and patients with score 3 or more were considered to have poor functional outcome [18]. Post-IV rtPA ICH was defined as any hemorrhage in the brain documented by CT or MRI within $36 \mathrm{~h}$ after thrombolysis. $\mathrm{ICH}$ was classified into symptomatic (sICH) and asymptomatic ICH.

sICH was defined as type 2 parenchymal hemorrhage (hemorrhage exceeding 30\% in the infarcted area with significant space occupying effect) with deterioration in NIHSS score of $\geq 4$ points or death [19,20]. PI was evaluated as a derived flow parameter using pulsed wave doppler; it is derived from the difference in the peak systolic velocity (PSV) and end diastolic velocity (EDV) divided by the mean flow velocity $(\mathrm{MFV}) ; \mathrm{PI}=(\mathrm{PSV}-$ EDV)/MFV [21], and its normal value range from 0.5 to 1.2 [22].

\section{Drug used and method}

Actilyse $50 \mathrm{mg}$ vial (IV rtPA) at a dose of $0.9 \mathrm{mg} / \mathrm{kg}$ to a maximum of $90 \mathrm{mg}$ intravenously (10\% bolus infused in $1 \mathrm{~min}$, the remaining 90\% infused in $1 \mathrm{~h}$ ).

\section{Statistical analysis of the data}

Data were presented as qualitative data (number and percent), quantitative, range (minimum and maximum), mean, standard deviation, median and interquartile range (IQR). Data was analyzed by chi-square test, Fisher's exact or Monte Carlo correction, Student's $t$ test, Mann-Whitney test, and Regression test. Data were collected and analyzed by IBM SPSS software package version 20.0. (Armonk, NY: IBM Corp). Significance of the obtained results was judged at the $5 \%$ level.

\section{Results}

Our study included 150 patients, male patients were 95 (63.3\%) and female patients were 55 (36.7\%), the age of our patients ranged between 24 and 80 years with median age 63 years. Other baseline characteristics in our study were detailed in Table 1.

\section{Univariate analysis}

The univariate analysis was done correlating the study variables (demographic, risk factors, and patients baseline characteristics) with the functional outcome and revealed significant correlations between the following variables and poor functional outcome; DM ( $P$ value $\left.0.023^{*}\right)$, hypertension $\left(0.009^{*}\right)$, AF $\left(P\right.$ value $\left.0.004^{*}\right)$, increased NIHSS score at time of admission ( $P$ value $<$ $\left.0.001^{*}\right)$, increased NIHSS score $24 \mathrm{~h}$ after receiving IV rtPA ( $P$ value $\left.<0.001^{*}\right)$, stroke lesion in the posterior circulation territory $(P$ value $<0.001 ")$, Increased value of PI in the cerebral vessels at the same side of stroke lesion $\left(P\right.$ value $\left.<0.001^{*}\right)$, presence of post-IV rtPA ICH (symptomatic and asymptomatic) $\left(P\right.$ value $\left.0.001^{*}\right)$, other variables did not show significant correlations with poor functional outcome as seen in (Tables 3 and 4).

There were also significant correlations between the following variables and good functional outcome; decreased NIHSS score at time of admission ( $P$ value < $\left.0.001^{\prime \prime}\right)$, decreased NIHSS score $24 \mathrm{~h}$ after receiving IV rtPA $\left(P\right.$ value $\left.<0.001^{*}\right)$, stroke lesion location in the anterior circulation territory $\left(P\right.$ value $\left.<0.001^{\prime \prime}\right)$, normal range value of $P I$ in the cerebral vessels at the same side of stroke lesion $\left(P\right.$ value $\left.<0.001^{\prime \prime}\right)$, absence of post-IV rtPA ICH ( $P$ value $\left.0.001^{*}\right)$, and other variables did not show significant correlations with good functional outcome as seen in (Tables 5 and 6).

\section{Multivariate analysis}

The multivariate analysis of the study variables to detect the independent predictive factors of the functional outcome showed the following results: among study variables (demographic and risk factors), AF ( $P$ value $<0.001^{\prime \prime O R} 6.28^{\prime \prime}(95 \%$ C.I $\left.)\right)$, hypertension $(P$ value $0.001^{\prime \prime O R} \quad 3.65^{\prime \prime}(95 \%$ C.I $\left.)\right)$, DM $\quad(P$ value $0.009^{\prime \prime}$ OR $2.805^{\prime \prime}(95 \%$ C.I $)$ ), those were the significant independent predictive risk factors of poor functional outcome (Table 3).

Among study variables (stroke illness and $\mathrm{ICH}$ following IV rtPA), increased NIHSS score $24 \mathrm{~h}$ after receiving IV rtPA ( $P$ value $0.003^{\prime \prime}$ OR $8.039^{\prime \prime}$ (95\% C.I)), increased value of PI in the cerebral vessels at the same side of stroke lesion ( $P$ value $0.038^{*}$ OR $42.48^{*}(95 \%$ C.I $)$ ), those were the significant independent predictive variables of poor functional outcome (Table 4).

On the other hand, decreased NIHSS score $24 \mathrm{~h}$ after receiving IV rtPA ( $P$ value $0.003^{*}$ OR $0.124^{*}(95 \%$ C.I)), normal value of PI in the cerebral vessels at the same side of stroke lesion ( $P$ value $0.038^{\prime \prime}$ OR $42.48^{\prime \prime}(95 \%$ C.I)), those were the significant independent predictive variables of good functional outcome (Table 6).

\section{Discussion}

Our study has demonstrated that use of intravenous thrombolytic therapy for acute stroke is associated with better functional and neurological outcomes and significantly reduce the effect of stroke morbidity and mortality; this was in agreement with several studies that supported the short- and long-term outcome benefits of IV rtPA like the large third international stroke trial [23], and the systematic review and meta-analysis study of real-world outcomes of acute ischemic stroke treatment with intravenous thrombolysis [24].

Our study showed highly significant correlation between NIHSS score and the functional outcome, at time of admission, consequently categorical classification of stroke severity, and $24 \mathrm{~h}$ after receiving IV rtPA. These correlations were found in the univariate analysis but 
Table 1 Patients demographic data and their baseline characteristics $(n=150)$

\begin{tabular}{|c|c|}
\hline & No. (\%) \\
\hline \multicolumn{2}{|l|}{ Gender } \\
\hline Male & $95(63.3)$ \\
\hline Female & $55(36.7)$ \\
\hline \multicolumn{2}{|l|}{ Age } \\
\hline Min.-Max. & $24.0-80.0$ \\
\hline Mean \pm SD. & $62.23 \pm 10.31$ \\
\hline Median & $63.0(55.0-70.0)$ \\
\hline \multicolumn{2}{|l|}{ NIHSS score at time of admission } \\
\hline Min.-Max. & $4.0-21.0$ \\
\hline Mean \pm SD. & $10.65 \pm 3.91$ \\
\hline Median (IQR) & 10.0(7.0-14.0) \\
\hline \multicolumn{2}{|l|}{ NIHSS score $24 \mathrm{~h}$ after IV rtPA } \\
\hline Min.-Max. & $0.0-21.0$ \\
\hline Mean \pm SD. & $5.25 \pm 4.99$ \\
\hline Median (IQR) & $3.0(2.0-9.0)$ \\
\hline \multicolumn{2}{|c|}{ Categorical classification of stroke severity at time of admission } \\
\hline Mild & $39(26.0)$ \\
\hline Moderate & $101(67.3)$ \\
\hline Severe & $10(6.7)$ \\
\hline \multicolumn{2}{|l|}{ Stroke lesion location } \\
\hline Posterior circulation territory & $24(16.0)$ \\
\hline Anterior circulation territory & $126(84.0)$ \\
\hline \multicolumn{2}{|c|}{ Pulsatility index at the same side of stroke lesion } \\
\hline Within normal range & $88(58.7)$ \\
\hline Increased & $62(41.3)$ \\
\hline \multicolumn{2}{|l|}{ Door to needle time } \\
\hline$<60 \min$ & $112(74.7)$ \\
\hline$\geq 60 \min$ & $38(25.3)$ \\
\hline \multicolumn{2}{|l|}{ Time of receiving IV rtPA from stroke onset } \\
\hline$<3 \mathrm{~h}$ & $90(60.0)$ \\
\hline $3-4.5 \mathrm{~h}$ & $60(40.0)$ \\
\hline \multicolumn{2}{|l|}{ Risk factor } \\
\hline Hyperlipidemia & $58(38.7)$ \\
\hline Diabetes mellitus & $51(34.0)$ \\
\hline Hypertension & $70(46.7)$ \\
\hline Atrial fibrillation & $27(18.0)$ \\
\hline Coronary artery disease & $17(11.3)$ \\
\hline Smoking & $50(33.3)$ \\
\hline \multicolumn{2}{|l|}{ Intracerebral hemorrhage following IV rtPA } \\
\hline Asymptomatic intracerebral hemorrhage & $9(6.0)$ \\
\hline Symptomatic intracerebral hemorrhage & $4(2.7)$ \\
\hline
\end{tabular}

Post-stroke functional outcome among patients in this study was assessed using mRS 3 months after receiving IV rtPA (Table 2) (Fig. 1 and 2). 
Table 2 Functional outcome and mRS score 3 months after IV rtPA among the patients $(n=150)$

\begin{tabular}{ll}
\hline & No. (\%) \\
\hline Functional outcome of IV rtPA & \\
Goor functional outcome (3-6) & $52(34.7)$ \\
mRS score 3 months after IV rtPA & $98(65.3)$ \\
From 0 to 2 (good) & \\
From 3 to 6 (poor) & $98(65.3)$ \\
0 & $52(34.7)$ \\
1 & $62(41.3)$ \\
2 & $30(20.0)$ \\
3 & $6(4.0)$ \\
4 & $36(24.0)$ \\
5 & $11(7.3)$ \\
6 & $5(3.3)$ \\
Min. - Max. & $0(0.0)$ \\
Mean \pm SD. & $0.0-5.0$ \\
Median (IQR) & $1.46-1.55$ \\
\hline
\end{tabular}

when multivariate analysis for the study variables was done, it showed that the NIHSS score $24 \mathrm{~h}$ after receiving IV rtPA was considered to be a strong independent predictor of the functional outcome, its increase was associated with poor functional outcome and vice versa, thus highly suggests that the initial clinical improvements in the first hours or $24 \mathrm{~h}$ after receiving IV rtPA is of great importance in determining the final degree of patient dependency in the future away from the degree of stroke severity at time of admission, and this was in agreement with the study conducted by Alejandro et al. 2015 [25].

In our study, there were highly significant correlations between anterior circulation ischemic stroke and good functional outcome, posterior circulation ischemic stroke, and poor functional outcome; these correlations were present in the univariate analysis, but were not significantly independent predictors of the functional outcome. This result was in agreement with the study conducted by Faisal et al. 2018 [26] who related this to a delayed door to needle time in case of posterior circulation ischemic stroke patients compared to anterior circulation stroke as clinical recognition of posterior circulation stroke is challenging specially for physicians in emergency department (ED) settings, and this may delay diagnosis time and treatment with intravenous tissue plasminogen activator affecting patients outcome and prognosis so early clinical recognition is crucial. However, several studies had reported that risk of bleeding complications post IV rtPA is higher in the anterior circulation ischemic stroke than in the posterior circulation ischemic but functional outcome was similar in both territories [27].

It is known that vascular reactivity is impaired in acute stroke, transmission of the excessive pulsatile flow may overwhelm the autoregulatory reserve, causing further brain damage [28]. Our study showed highly significant correlations between the increased value of PI using TCCD and poor functional outcome in the univariate analysis, also the normal range value of PI and good functional outcome. Then, the multivariate analysis was done and revealed that the PI value is a strong independent predictor of functional outcome when increased it predicts a poor functional outcome, and when it is within normal range, it predicts a good functional outcome.

This was in agreement with previous studies like Nevzat et al. 2013 [29] Also, Kim et al. 2016 demonstrated that PI was an independent determinant of infarct volume in acute lacunar stroke and consequently the functional outcome [30].

Table 3 Univariate and multivariate analysis between study variable (demographic and risk factors) and poor functional outcome

\begin{tabular}{|c|c|c|c|c|}
\hline & \multicolumn{2}{|c|}{ Univariate } & \multicolumn{2}{|c|}{${ }^{\#}$ Multivariate } \\
\hline & $\mathbf{P}$ & OR (95\% C.I) & $P$ & OR (95\% C.I) \\
\hline Age & 0.358 & $1.016(0.982-1.050)$ & & \\
\hline Male gender & 0.462 & $1.304(0.643-2.64)$ & & \\
\hline Hyperlipidemia & 0.309 & $1.428(0.719-2.834)$ & & \\
\hline Diabetes & $0.023^{*}$ & $2.254^{*}(1.11-4.55)$ & $0.009^{*}$ & $2.805^{*}(1.288-6.10)$ \\
\hline Hypertension & $0.009^{*}$ & $2.526^{*}(1.266-5.041)$ & $0.001^{*}$ & $3.65^{*}(1.65-8.06)$ \\
\hline Atrial Fibrillation & $0.004^{*}$ & $3.515^{*}(1.48-8.31)$ & $<0.001^{*}$ & $6.28^{*}(2.31-1.83)$ \\
\hline Coronary artery disease & 0.100 & $2.355(0.850-6.526)$ & & \\
\hline Smoking & 0.091 & $1.833(0.907-3.70)$ & & \\
\hline
\end{tabular}

$O R$ odd's ratio, C.I confidence interval

"All variables with $P<0.05$ was included in the multivariate

$R$ reference type

*Statistically significant at $P \leq 0.05$ 
Table 4 Univariate and multivariate analysis between study variable (stroke illness and ICH following IV rtPA) and poor functional outcome

\begin{tabular}{|c|c|c|c|c|}
\hline & \multicolumn{2}{|c|}{ Univariate } & \multicolumn{2}{|c|}{${ }^{\text {"Multivariate }}$} \\
\hline & $\bar{P}$ & OR (95\% C.I) & $\bar{P}$ & OR (95\% C.I) \\
\hline NIHSS score $24 \mathrm{~h}$ after IV rtPA & $<0.001^{*}$ & $3.63^{*}(2.10-6.27)$ & $0.003^{*}$ & $8.039^{*}(2.01-32.07)$ \\
\hline Categorical classification of stroke severity at time of admission & $0.001^{*}$ & $9.338^{*}(3.31-26.32)$ & 0.647 & $4.34(0.008-2321.5)$ \\
\hline NIHSS score at time of admission & $<0.001^{*}$ & $1.477^{*}(1.297-1.68)$ & 0.148 & $0.511(0.206-1.26)$ \\
\hline Stroke lesion location in posterior circulation territory & $<0.001^{*}$ & $6.314^{*}(2.411-16.53)$ & 0.206 & $13.36(0.24-740.6)$ \\
\hline Increased pulsatility index at the same side of stroke lesion & $<0.001^{*}$ & $52.01^{*}(17.77-152.17)$ & $0.038^{*}$ & $42.48^{*}(1.24-1455.0)$ \\
\hline Time of receiving IV rtPA from stroke onset (3-4.5 h) & 0.647 & $0.864(0.436-1.711)$ & & \\
\hline Intracerebral hemorrhage following IV rtPA (symptomatic +asymptomatic) & $0.001^{*}$ & $29.10^{*}(3.66-231.9)$ & 0.570 & $0.034(0.0-3907.1)$ \\
\hline
\end{tabular}

OR odd's ratio, C.I confidence interval

\# All variables with $P<0.05$ was included in the multivariate

$R$ reference type

*Statistically significant at $P \leq 0.05$

Our study showed significant negative correlation between hypertension and the functional outcome in the univariate analysis and when tested as independent predictors of the functional outcome among risk factors using the multivariate analysis; it was a strong independent predictor of poor functional outcome. This was in agreement with previous studies which revealed association between presence of hypertension and poor functional outcome 3 months after IV rtPA [31, 32] and that result was in contrary to several studies which found non-significant correlation between history of hypertension and the functional outcome [33, 34]. It was hypothesized that patients with chronic hypertension have shifts in perfusion autoregulation parameters as well as changes in collateral blood supplies and this, in conjunction with other considerations such as carotid artery stenosis, put hypertensive stroke patients at a unique risk special consideration should be considered when determining rtPA eligibility in these patients $[35,36]$.
Our study showed significant negative correlation between DM and the functional outcome. This was present in the univariate analysis, and when tested as independent predictors of the functional outcome among risk factors using the multivariate analysis, it was a strong independent predictor of poor functional outcome. This was in agreement with many studies which had identified DM as a predictor of poor functional outcome after receiving IV rtPA among stroke patients like that conducted by Roquer and et al. 2014 and that was conducted by Gustavo et al. 2013 [32, 37]. However, other studies did not show significant correlations between $\mathrm{DM}$ and functional outcome after receiving IV rtPA, but had showed a significant correlation between admission hyperglycemia and poor functional outcome after receiving IV rtPA [31, 38].

The hypothesis was that DM increases the concentration of serum plasminogen activator inhibitor 1 and decreases fibrinolysis [39]. Also, there is a relationship between basal blood glucose and cerebral edema in IV thrombolytic patients, and this arise

Table 5 Univariate and multivariate analysis between study variable (demographic and risk factors) and good functional outcome

\begin{tabular}{|c|c|c|c|c|}
\hline & \multicolumn{2}{|c|}{ Univariate } & \multicolumn{2}{|c|}{${ }^{\#}$ Multivariate } \\
\hline & $\bar{P}$ & OR (95\% C.I) & $\bar{P}$ & OR $(95 \%$ C.I) \\
\hline Age & 0.358 & $0.984(0.952-1.018)$ & & \\
\hline Female gender & 0.462 & $1.304(0.643-2.64)$ & & \\
\hline Hyperlipidemia & 0.309 & $0.700(0.353-1.391)$ & & \\
\hline Diabetes & $0.023^{*}$ & $0.444^{*}(0.22-0.89)$ & $0.009^{*}$ & $0.357^{*}(0.164-0.776)$ \\
\hline Hypertension & $0.009^{*}$ & $0.396^{*}(0.198-0.790)$ & $0.001^{*}$ & $0.274^{*}(0.124-0.60)$ \\
\hline Atrial fibrillation & $0.004^{*}$ & $0.284^{*}(0.120-0.673)$ & $<0.001^{*}$ & $0.159^{*}(0.059-0.431)$ \\
\hline Coronary artery disease & 0.100 & $0.425(0.153-1.17)$ & & \\
\hline Smoking & 0.091 & $0.545(0.27-1.102)$ & & \\
\hline
\end{tabular}

$O R$ odd's ratio, $C . I$ confidence interval

\#All variables with $P<0.05$ was included in the multivariate

$R$ reference type

*Statistically significant at $P \leq 0.05$ 
Table 6 Univariate and multivariate analysis between study variable (stroke illness and intracerebral hemorrhage following IV rtPA) and good functional outcome

\begin{tabular}{|c|c|c|c|c|}
\hline & \multicolumn{2}{|l|}{ Univariate } & \multicolumn{2}{|c|}{ "Multivariate } \\
\hline & $\bar{P}$ & OR (95\% C.I) & $\bar{P}$ & OR (95\% C.I) \\
\hline NIHSS score $24 \mathrm{~h}$ after IV rtPA & $<0.001^{*}$ & $0.275^{*}(0.159-0.476)$ & $0.003^{*}$ & $0.124^{*}(0.031-0.496)$ \\
\hline Categorical classification of stroke severity at time of admission & $<0.001^{*}$ & $0.107^{*}(0.038-0.302)$ & 0.647 & $0.230(0.0-123.17)$ \\
\hline NIHSS score at time of admission & $<0.001^{*}$ & $0.677^{*}(0.594-0.771)$ & 0.148 & $1.95(0.78-4.84)$ \\
\hline Stroke lesion location in the anterior circulation territory & $<0.001^{*}$ & $6.314^{*}(2.411-16.53)$ & 0.206 & $13.33(0.24-740.6)$ \\
\hline Normal range value of pulsatility index at the same side of stroke lesion & $<0.001^{*}$ & $52.01^{*}(17.77-152.17)$ & $0.038^{*}$ & $42.48^{*}(1.24-1455.0)$ \\
\hline Time of receiving IV rtPA from stroke onset $(<3 \mathrm{~h})$ & 0.647 & $0.864(0.436-1.711)$ & & \\
\hline Absence of intracerebral Hemorrhage following IV rtPA & $0.001^{*}$ & $0.034^{*}(0.004-0.273)$ & 0.570 & $29.10(0.0-3310707)$ \\
\hline
\end{tabular}

OR odd's ratio, C.I confidence interval

\#All variables with $P<0.05$ was included in the multivariate

$R$ reference type

* Statistically significant at $P \leq 0.05$

from the fact that high glucose may impair the blood-brain barrier [40, 41].

Our study showed non-significant correlation between CAD and the functional outcome 3 months after receiving IV rtPA, and this was in agreement with various studies [33], and in contrary to several studies which had revealed significant correlations between $\mathrm{CAD}$ and the functional outcome 3 months after IV rtPA [31, 42].

Our study showed non-significant correlation between recent or current smoking and the functional outcome 3 months after receiving IV rtPA, and this was in agreement with previous studies [31, 42], and in contrary to other studies which revealed significant negative correlation between recent or current smoking and functional outcome 3 months after IV rtPA [43].

The exact mechanisms of AF on the outcomes of stroke patients were not clear, and stroke patients with
AF may have large and old thrombi, which are not sensitive to the treatment of thrombolytic therapy [44]. Our study showed significant negative correlation between $\mathrm{AF}$ and the functional outcome in the univariate analysis. AF when was tested in this as an independent predictor of the functional outcome and the risk factors variables using the multivariate analysis, it was shown to be the strongest independent predictor of poor functional outcome. This was in agreement with many previous studies like that conducted by Wu et al. 2020 [45], and that study that was conducted by Yue et al. 2016 [46]. On the other hand, there were studies showed significant correlation between $\mathrm{AF}$ and favorable functional outcome after receiving IV rtPA [47, 48].

In our study, there was significant correlation between post-rtPA ICH (asymptomatic, symptomatic) and poor functional outcome in the univariate

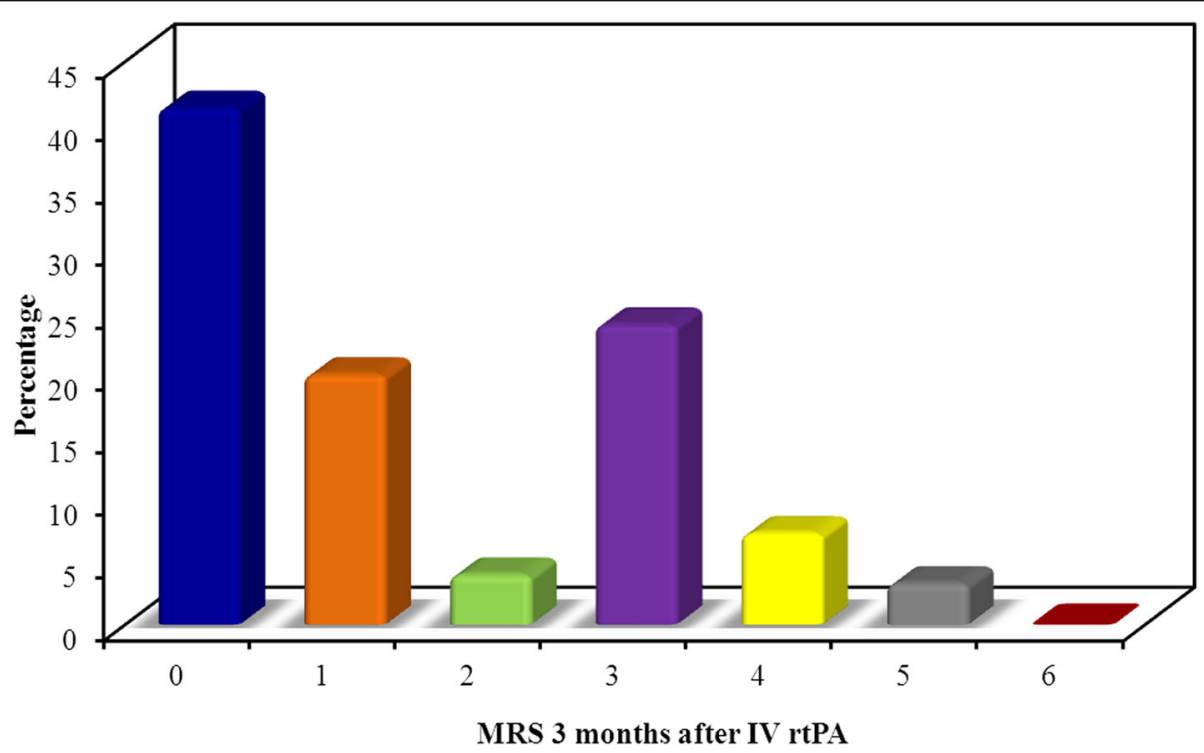

Fig. $1 \mathrm{mRS}$ score 3 months after IV rtPA among the patients $(n=150)$. 


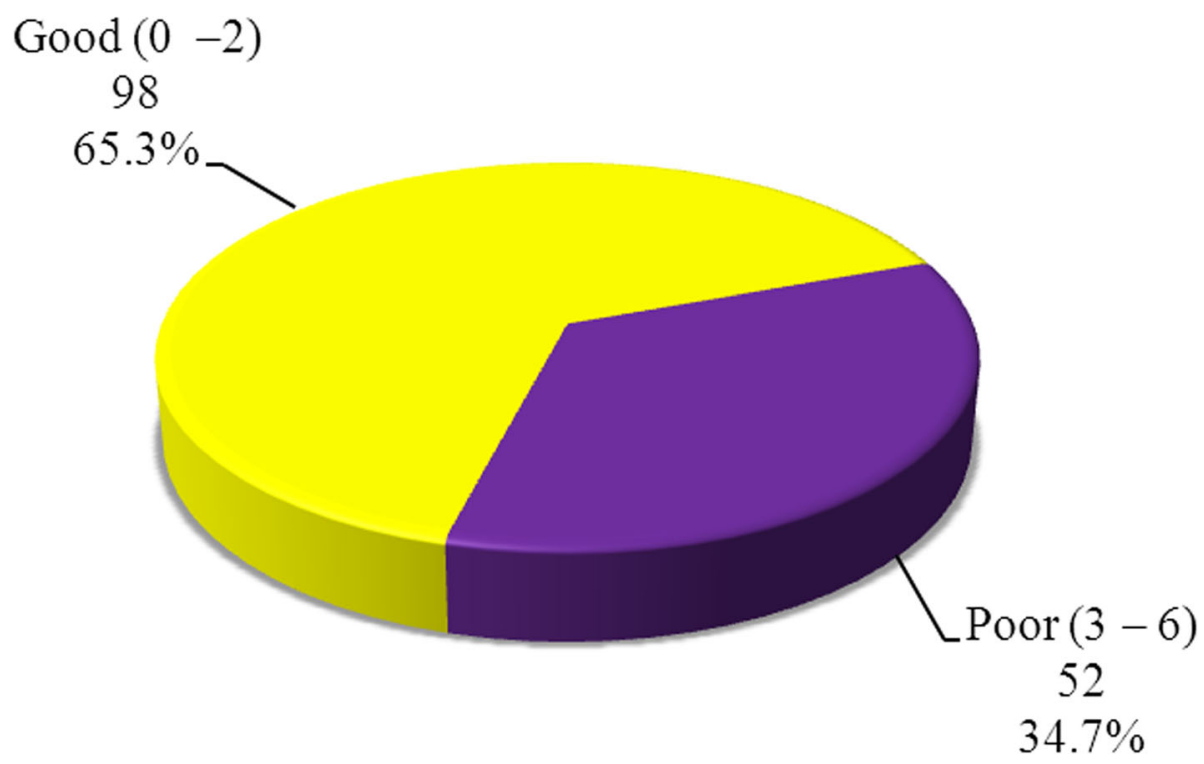

Fig. 2 Functional outcome 3 months after IV rtPA among the patients $(n=150)$.

analysis; however, it was non-significant independent predictor of the functional outcome among our study variables in the multivariate analysis. This was in agreement with the majority of studies exploring that issue and found poor functional outcome and increased mortality rates among patients who developed sICH after receiving IV $\operatorname{rtPA}[49,50]$.

\section{Conclusion}

Intravenous thrombolytic therapy improves the functional outcome among acute ischemic stroke patients. Also, AF, hypertension, DM, NIHSS $24 \mathrm{~h}$ after receiving IV rtPA and PI value in the cerebral vessels at the same side of stroke lesion could be used as independent predictors of the functional outcome.

\section{Limitations of the study}

Our study was performed in a single center and included only those who completed the follow-up at 3 months after receiving IV rtPA. However, that follow-up period (3 months) is relatively short to some extent. Also, the study included the major potential variables affecting the functional outcome but, there are other variables could affect the outcomes like biomarkers, genetics, history of previous stroke, and infarction volume. These potential variables are recommended to be included in future studies with large number of patients sample and to be followed up over longer period.

\section{Abbreviations}

AF: Atrial fibrillation; AHA: American heart association; ASA: American stroke association; CAD: Coronary artery disease; CT: Computerized tomography; CTA: Computerized tomography angiography; DALYs: Disability Adjusted Life Years; DM: Diabetes mellitus; ED: Emergency Department; EDV: End diastolic velocity; ICH: Intracerebral hemorrhage; IV rtPA: Intravenous recombinant tissue plasminogen activator; MFV: Mean flow velocity; MRA: Magnetic resonance angiography; MRI: Magnetic resonance angiography; NIHS S: National institute of health stroke scale; PI: Pulsatility index; PSV: Peak systolic velocity; sICH: Symptomatic intracerebral hemorrhage;

TCCD: Transcranial color coded duplex.

\section{Acknowledgements}

We wish to express our great appreciation to our patients and their family for supporting us during this work, and also we should express our deep thanks for the neurosonology team members for their cooperation in early TCCD evaluation of our patients and guidance during this work. Finally, we should thank Dr. Tamer Roshdy for his great effort in patients' data registry and extraction during our study which added a lot to our research.

\section{Authors' contributions}

MA: conceived of the study and participated in its design and coordination and helped to draft the manuscript (FG). HA: conceived of the study and participated in its design and coordination and helped to draft the manuscript (FG). HK: conceived of the study and participated in its design and coordination and helped to draft the manuscript (FG). MF: participated in the design of the study and performed the statistical analysis (ES). AS: conceived of the study and participated in its design and coordination and helped to draft the manuscript (FG). All authors have read and approved the manuscript.

\section{Funding}

This research did not receive any specific grant from funding agencies in the public, commercial, or non-profit sectors.

\section{Availability of data and materials}

All raw data will be available on the editor request through communication with the corresponding author.

\section{Ethics approval and consent to participate}

The study protocol was approved by the Ain Shams University, Faculty of Medicine Research Ethic Committee FWA 000017585 in February 2018.

Participation was voluntary and all contributors or their first-degree relatives received detailed information about the aims of this research work and an informed consent was obtained prior to the commencement of the study. 


\section{Consent for publication}

A written informed consent for the publication was obtained from all the participants (or their first degree relatives).

\section{Competing interests}

All authors declare that they have no competing interest.

Received: 27 May 2020 Accepted: 22 September 2020

Published online: 04 November 2020

\section{References}

1. Donnan GA, Fisher M, Macleod M, et al. Stroke. Lancet. 2008:371:1612-23.

2. Mozaffarian D, Benjamin EJ, Go AS, et al. American Heart Association Statistics Committee and Stroke Statistics Subcommittee. Heart disease and stroke statistics-2015 update: a report from the American Heart Association. Circulation. 2015;131(4):e29-322.

3. Mackay J, Mensah GA. The Atlas of Heart Disease and Stroke. Geneva: World Health Organization; 2004.

4. Abdullah F, Moustafa RR. Burden of stroke in Egypt: current status and opportunities. Int J Stroke. 2014;9:1105-8.

5. Annual Bulletin of Mortality Statistics. Central Agency for Public Mobilization and Statistics (CAPMAS), http:// www.capmas.gov.eg (2013, accessed 20 May 2017).

6. Lansberg MG, Bluhmki E, Thijs VN. Efficacy and safety of tissue plasminogen activator 3 to 4.5 hours after acute ischemic stroke: a metaanalysis. Stroke. 2009;40:2438-41.

7. Lees KR, Emberson J, Blackwell L, et al. Effects of Alteplase for Acute Stroke on the Distribution of Functional Outcomes: A Pooled Analysis of 9 Trials. Stroke. 2016:47:2373

8. Balami JS, Hadley G, Sutherland BA, et al. The exact science of stroke thrombolysis and the quiet art of patient selection. Brain. 2013;136:3528-53.

9. Wardlaw JM, Murray $V$, Berge $E$, et al. Thrombolysis for acute ischaemic stroke. Cochrane Database Syst Rev. 2014;7:CD000213.

10. Goyal M, Almekhlafi M, Dippel DW, et al. Rapid Alteplase Administration Improves Functional Outcomes in Patients With Stroke due to Large Vessel Occlusions. Stroke. 2019:50:645.

11. Molina CA, Alexandrov AV, Demchuk AM, et al. Improving the predictive accuracy of recanalization on stroke outcome in patients treated with tissue plasminogen activator. Stroke. 2004;35:151-6.

12. Ploneda Perilla AS, Schneck MJ. Unanswered questions in thrombolytic therapy for acute ischemic stroke. Neurol Clin. 2013;31:677-704.

13. Lyden P, Brott T, Tilley B, et al. Improved reliability of the NIH Stroke Scale using video training. NINDS TPA Stroke Study Group. Stroke. 1994;25:2220-6.

14. Lyden P, Lu M, Jackson C, et al. Underlying structure of the National Institutes of Health Stroke Scale: results of a factor analysis. NINDS tPA Stroke Trial Investigators. Stroke. 1999;30:2347-54.

15. Bonita R, Beaglehole R. Modification of Rankin Scale: Recovery of motor function after stroke. Stroke. 1988;19(12):1497-500.

16. Van Swieten JC, Koudstaal PJ, Visser MC, et al. Interobserver agreement for the assessment of handicap in stroke patients. Stroke. 1988;19(5): 604-7.

17. Marián M, Marta R, David RL, et al. Baseline National Institutes of Health Stroke Scale-Adjusted Time Window for Intravenous Tissue-Type Plasminogen Activator in Acute Ischemic Stroke. Stroke. 2014:45:1059-63.

18. Banks JL, Marotta CA. Outcomes validity and reliability of the modified rankin scale: implications for stroke clinical trials-a literature review and synthesis. Stroke. 2007;38(3):1091-6.

19. Wahlgren N, Ahmed N, Davalos A, et al. Thrombolysis with alteplase for acute ischaemic stroke in the Safe Implementation of Thrombolysis in Stroke-Monitoring Study (SITS-MOST): an observational study. Lancet. 2007; 369(9558):275-82.

20. The NINDS t-PA Stroke Study Group. Intracerebral hemorrhage after intravenous t-PA therapy for ischemic stroke. Stroke. 1997;28:210918.

21. Kidwell CS, El-Saden S, Livshits Z, et al. Transcranial Doppler pulsatility indices as a measure of diffuse small-vessel disease. J Neuroimaging. 2001;11:229-35.

22. Bathala L, Mehndiratta MM, Sharma VK. Transcranial doppler: Technique and common findings (Part 1). Ann Indian Acad Neurol. 2013;16(2):174-9.

23. The IST-3 Collaborative Group. Effect of thrombolysis with alteplase within $6 \mathrm{~h}$ of acute ischemic stroke on long-term outcomes (the third International Stroke Trial [IST-3]): 18-month follow-up of a randomised controlled trial. Lancet Neurol. 2013;12:768-76.
24. Qin B, Zhao MJ, Chen H, et al. Real-World Outcomes of Acute Ischemic Stroke Treatment with Intravenous Thrombolysis: A Systematic Review and Meta-Analysis. J Stroke Cerebrovasc Dis. 2018;27(12):3542-8.

25. Alejandro GT, Natalia GC, Carlos CC, et al. Factors associated with long-term prognosis after ischemic stroke treated with fibrinolytic agents. Emergencias. 2015;27:34-8.

26. Faisal I, Naveed A, Najib M, et al. Thrombolysis in posterior circulation stroke patients is associated with prolonged door to needle time. Neurology Apr 2018, 90(15) P4.230.

27. Keselman B, Gdovinová Z, Jatuzis D, et al. Safety and outcomes of intravenous thrombolysis in posterior versus anterior circulation stroke: results from the safe implementation of treatments in stroke registry and meta-analysis. Stroke. 2020; STROKEAHA-119.

28. Petersen NH, Ortega-Gutierrez S, Reccius A, et al. Dynamic cerebral autoregulation is transiently impaired for one week after large-vessel acute ischemic stroke. Cerebrovasc Dis. 2015;39:144-50.

29. Nevzat U, Özcan Ö, Gülnur TU. Relationship between Pulsatility Index and Clinical Course of Acute Ischemic Stroke after Thrombolytic Treatment. BioMed Research International. 2013:ArticleID265171,5.

30. Kim Y, Lee $H$, An SA, et al. The effect of pulsatility index on infarct volume in acute lacunar stroke. Yonsei Med J. 2016:57(4):950-5.

31. Bruno C, Colavita G, Romero G, et al. Predictors of clinical outcome after intravenous thrombolysis in ischemic stroke without large vessel occlusion: the role of admission glycemia. M J E-Med. 2018;3(1):030.

32. Saposnik G, Reeves MJ, Johnston SC, et al. Predicting clinical outcomes after thrombolysis using the iscore results from the virtual international stroke trials archive. Stroke. 2013;44:2755-9.

33. Mei-Ling ST, Khean JG, Khairul AK, et al. Predictors of functional outcome in patients with stroke thrombolysis in a tertiary hospital in Malaysia. Singapore Med J. 2019 May;60(5):236-40.

34. Masoud M, Motahare A, Seyedeh FS, et al. Factors predicting the outcome of intravenous thrombolysis in stroke patients before rt-PA administration. Caspian J Intern Med. 2019;10(4):424-30

35. Novak V, Hu K, Desrochers L, et al. Cerebral flow velocities during daily activities depend on blood pressure in patients with chronic ischemic infarctions. Stroke. 2010:41(1):61-6.

36. Gacon J, Badacz R, Stepien E, et al. Diagnostic and prognostic micro-RNAs in ischaemic stroke due to carotid artery stenosis and in acute coronary syndrome: a four-year prospective study. Kardiol Pol. 2018;76(2):362-9.

37. Roquer J, Rodríguez-Campello A, Cuadrado-Godia E, et al. Ischemic stroke in prediabetic patients. J Neurol. 2014;261:1866-70

38. El-Khawas H, Nasef A, Gaber A, et al. Department of Neurology, Ain Shams University. Admission Hyperglycemia in Acute Ischemic Stroke: Effects on Short Term Prognosis. Egypt J. Neurol. Psychiat. Neurosurg. 2006;43(1):603-13.

39. Trost S, Pratley R, Sobel B. Impaired fibrinolysis and risk for cardiovascular disease in the metabolic syndrome and type 2 diabetes. Curr Diab Rep. 2006;6(1):47-54

40. Thoren M, Azevedo E, Dawson J, et al. Predictors for cerebral edema in acute Ischemic stroke treated with Intravenous thrombolysis. Stroke. 2017; 48(9):2464-71

41. Kruyt ND, Biessels GJ, Devries JH, et al. Hyperglycemia in acute ischemic stroke: pathophysiology and clinical management. Nat Rev Neurol. 2010; 6(3):145-55.

42. Syed FA, Khawja S, Hakan A, et al. Baseline Predictors of Poor Outcome in Patients Too Good to Treat With Intravenous. Thrombolysis Stroke. 2016:47:2986-92.

43. Ryu M, Tetsuro A, Fumi K, et al. Smoking status and functional outcomes after acute ischemic stroke. Stroke. 2020;0: STROKE AHA.119.027230.

44. Kimura K, Iguchi Y, Shibazaki K, et al. IV t-PA therapy in acute stroke patients with atrial fibrillation. J Neurol Sci. 2009;276:6-8

45. Wu HM, Chung CP, Lin YY. Similar thrombolysis outcomes in acute stroke patients with and without atrial fibrillation if pre-stroke CHA2DS2-VASC score is low: A retrospective study. Medicine. 2020:99(2):e18680.

46. Yue R, Li D, Yu J, et al. Atrial Fibrillation is Associated With Poor Outcomes in Thrombolyzed Patients With Acute Ischemic Stroke: A Systematic Review and Meta-Analysis. Medicine (Baltimore). 2016;95(10):e3054

47. Sung SF, Chen YW, Tseng MC, et al. Atrial fibrillation predicts good functional outcome following intravenous tissue plasminogen activator in patients with severe stroke. Clin Neurol Neurosurg. 2013; 115:892-5

48. Zhang JB, Ding ZY, Yang Y, et al. Thrombolysis with alteplase for acute ischemic stroke patients with atrial fibrillation. Neurol Res. 2010;32:353-8. 
49. Lees KR, Bluhmki $\mathrm{E}$, von Kummer $\mathrm{R}$, et al. Time to treatment with intravenous alteplase and outcome in stroke: an updated pooled analysis of ECASS, ATLANTIS, NINDS, and EPITHET trials. Lancet. 2010;375(9727):1695703.

50. Berger C, Fiorelli M, Steiner $T$, et al. Hemorrhagic transformation of ischemic brain tissue: asymptomatic or symptomatic? Stroke. 2001;32: 1330-5.

\section{Publisher's Note}

Springer Nature remains neutral with regard to jurisdictional claims in published maps and institutional affiliations.

Submit your manuscript to a SpringerOpen ${ }^{\circ}$ journal and benefit from:

- Convenient online submission

- Rigorous peer review

- Open access: articles freely available online

- High visibility within the field

- Retaining the copyright to your article

Submit your next manuscript at $\boldsymbol{\sim}$ springeropen.com 